
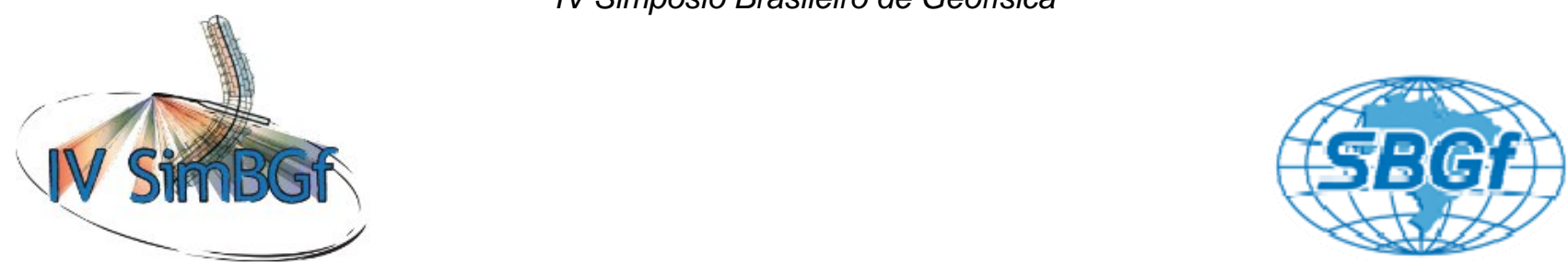

\title{
IMAGEAMENTO GEOELÉTRICO 2D COMO FERRAMENTA AUXILIAR NA ANÁLISE DE VULNERABILIDADE LOCAL DO AQÜÍFERO BARREIRAS NA ÁREA DA BACIA DO RIO CATU-RN.
}

Leandson Roberto Fernandes de Lucena ${ }^{1,2}$ (leandson@geofisica.ufrn.br); Josibel Gomes de Oliveira Junior ${ }^{1,2}$; Walter Eugênio de Medeiros ${ }^{1,2}$; Daniel Alexsander Silva dos Santos ${ }^{2}$; Marília de Araújo Costa Rodrigues ${ }^{1}$; Alessandro José Soares Dantas ${ }^{1}$; Antônio Lisboa Fernandes Junior ${ }^{1}$.

${ }^{1}$ Departamento de Geofísica-UFRN

${ }^{2}$ Pós-Graduação em Geodinâmica e Geofísica-UFRN

Copyright 2008, SBGf - Sociedade Brasileira de Geofísica

Este texto foi preparado para a apresentação no IV Simpósio Brasileiro de Geofísica, Belém, 14 a 17 de novembro de 2010. Seu conteúdo foi revisado pelo Comitê Técnico do IV SimBGf, mas não necessariamente representa a opinião da SBGf ou de seus associados. É proibida a reprodução total ou parcial deste material para propósitos comerciais sem prévia autorização da SBGf.

\section{Resumo}

Esta pesquisa apresenta os resultados iniciais obtidos com um imageamento geoelétrico 2D efetuado na área da bacia do Rio Catu-RN, no contexto hidrogeológico do Aqüífero Barreiras. O referido levantamento objetivou subsidiar preliminarmente a avaliação da vulnerabilidade do referido aqüífero e definir um arranjo de eletrodos mais apropriado a ser adotado nesse estudo. Dentro desse contexto, o arranjo Wenner mostrou-se mais adequado, sobretudo por apresentar um modelo de camadas plano-paralelas mais uniformizado, o qual possibilitou conferir uma vulnerabilidade local do aqüífero como elevada, a partir dos valores de espessura e resistividades da zona não saturada. Estes últimos estão associados com sedimentos arenosos de elevada condutividade hidráulica, quando confrontados com calibrações geoelétricas regionais disponíveis, favorecendo, portanto, a percolação de determinada carga contaminante.

\section{Introdução}

O presente trabalho integra uma pesquisa hidrogeológica desenvolvida no âmbito do Aqüífero Barreiras na área da bacia do Rio Catu-RN, região litorânea sul do Estado do Rio Grande do Norte (figura 1). A referida pesquisa é financiada pelo Conselho Nacional de Desenvolvimento Científico e Tecnológico-CNPq, sendo um dos seus objetivos principais qualificar 0 impacto da fertilização química, sobretudo aquela de natureza nitrogenada, no Aqüífero Barreiras, além de avaliar sua vulnerabilidade local.

Nesse contexto, o objetivo principal do presente estudo é avaliar qualitativamente o sinal geoelétrico obtido com as configurações de eletrodos Wenner e Schlumberger na elaboração de um imageamento 2D local do Aqüífero Barreiras, como ferramenta auxiliar para uma análise de vulnerabilidade local mais ampla do referido aquífero. Secundariamente, características deste sistema hidrogeológico foram preliminarmente avaliados na área do levantamento, particularmente a profundidade do nível freático, a espessura da zona não saturada e valores de resistividade elétrica dos principais horizontes hidroestratigráficos da porção superior do aqüífero. Tais resultados irão embasar a adoção prioritária de uma configuração de eletrodos em imageamentos futuros nesse ambiente hidrogeológico, além de subsidiarem o incremento da caracterização hidrogeofísica do Aqüífero Barreiras no litoral leste do Rio Grande do Norte.

Este aqüífero responde pelo abastecimento d'água de cerca de $80 \%$ das cidades e comunidades rurais inseridas na mesoregião leste potiguar, incluindo a capital Natal, fato este que motiva um crescente aprofundamento das pesquisas no seu contexto. Sua constituição litológica é bastante diversificada, envolvendo desde argilitos a arenitos conglomeráticos, embora se observe o predomínio de arenitos argilosos de idade Terciária-Quaternária, sendo capeados por sedimentos quaternários a recentes representados por coberturas arenosas, dunas, aluviões e mangues (Lucena et al, 1999; Lucena et al., 2006). O limite inferior deste aqüífero é o topo da seqüência carbonática mesozóica não aflorante da região, a qual foi individualizada em perfurações de poços como sendo constituído por sedimentos areno-argilosos a argilosos de composição calcífera e baixa potencialidade hidrogeológica, ou mesmo o embasamento cristalino, nas áreas próximas do contato deste último com a bacia sedimentar costeira. O aqüífero apresenta vazões de explotação elevadas em determinadas localidades, sobretudo naquelas de maior espessura dos sedimentos da Formação Barreiras, conforme observado em algumas captações na região sul de Natal e Parnamirim-RN (vazões da ordem de $100 \mathrm{~m}^{3} / \mathrm{h}$ ).

No tocante à condição hidrodinâmica, o Aqüífero Barreiras comporta-se de maneira bastante variável, sobretudo na região sul de Natal até a fronteira com a Paraíba. Este comportamento pode apresentar-se de livre a semiconfinado, onde a camada semiconfinante no topo, quando presente, é representada por lentes argilosas da própria Formação Barreiras (IPT, 1982). Toda a área pesquisada evidencia uma ampla relação entre mananciais superficiais e subterrâneos do Aqüífero Barreiras, onde o regime perene dos canais fluviais locais é creditado ao caráter influente do aqüífero. A área da bacia do Rio Catu e, mais precisamente, a localidade de Olho D'Água onde foi realizado o levantamento 
geoelétrico é amplamente utilizada na cultura da canade-açúcar, com utilização de fertilizantes químicos. Este último fato é bastante preocupante, sobretudo quando se observa uma espessura não saturada reduzida, a qual representa uma primeira defesa natural do aqüífero, incrementando o grau de vulnerabilidade local do mesmo.

\section{Metodologia}

Tradicionalmente 0 método da eletrorresistividade tem sido bastante utilizado em estudos hidrogeológicos (Astier, 1975; Custódio e Llamas, 1983; Feitosa e Manoel Filho, 1997). Ele consiste em determinar a resistividade elétrica de rochas por meio de medidas de potencial e corrente elétrica, sendo estes valores de resistividade variáveis de acordo com a porosidade, quantidade e salinidade dos fluidos intersticiais. Esta observação levou ao uso difundido de uma relação empírica de resistividade e porosidade, conhecida como Lei de Archie (in Orellana, 1972). No presente levantamento, utilizou-se um resistivímetro modelo Syscal Pro, fabricado pela Iris Instruments. Este último foi configurado para operar com setenta e dois eletrodos e adquirir uma pseudo-seção geoelétrica, composta por dez diferentes níveis de investigação, utilizando os arranjos de eletrodos Wenner e Schlumberger. Para visualização dos dados adotou-se o software ProSys II, também desenvolvido pela Iris Instruments, enquanto que os modelos de inversão foram obtidos com o software RES2DINV (GEOTOMO SOFTWARE, 2010). As referidas seções possuem 720 metros de extensão e possibilitaram investigar cerca de 45 metros de profundidade.

A vulnerabilidade de um aqüífero é definida como sendo as características intrínsecas que determinam a sensibilidade de um aqüífero ser adversamente afetado por uma carga contaminante antrópica imposta (Foster, 1987; Foster e Hirata, 1988), sendo função, primordialmente, da acessibilidade da zona saturada e da capacidade de atenuação da zona não saturada. Neste aspecto, têm-se como concepções básicas os seguintes tópicos:

- O contaminante é introduzido à superfície do terreno;

- O contaminante é transportado verticalmente até o aqüífero pela infiltração;

- O contaminante possui a mobilidade da água.

Dessa forma, uma cartografia de vulnerabilidade do aqüífero representaria o caminho vertical de uma carga potencialmente contaminante.

Dentre os diversos métodos empíricos propostos para avaliar a vulnerabilidade de aqüíferos, utilizou-se a metodologia simplificada GOD (Foster, 1987; Foster e Hirata, 1988), a qual se baseia nos seguintes parâmetros:

- G - Tipo e ocorrência do aqüífero (Groundwater occurrence);

- O - Litologia e grau de consolidação da zona vadosa ou camadas confinantes (Overall aquifer class);

- D - Profundidade do topo do aqüífero (Depth to aquifer).

O índice pontual é obtido multiplicando-se os três parâmetros, sendo o(s) valor(es) inserido(s) em uma das cinco classes de vulnerabilidade (figura 2): extrema
$(0,7-1)$, alta $(0,5-0,7)$, moderada $(0,3-0,5)$, baixa $(0,1$ $-0,3)$ e desprezível $(0-0,3)$.

\section{Resultados e Discussão}

As duas seções de resistividade, obtidas com modelos de inversão do software RES2DINV, conforme reportado, abrangem a porção superior da formação aqüífera e zona não saturada sobreposta (figura 3). Estas seções evidenciaram uma hidroestratigrafia aproximadamente plano-paralela, tendo como base a disposição de camadas geoelétricas e respectivos intervalos de valores de resistividade aparente. O topo da formação aqüífera foi caracterizado através da diminuição da resistividade aparente (valores da ordem de 400 Ohm.metro), sobretudo quando confrontado com resistividades substancialmente maiores da zona não saturada sobreposta (resistividades superiores a 1000 Ohm.metro), de acordo com calibrações e valores representativos de resistividades do aqüífero e respectiva zona não saturada definidas por Lucena (2005). A profundidade máxima desse contato situa-se no intervalo de 10 a 15 metros. A quebra da horizontalidade das camadas geoelétricas nas proximidades da posição 500 metros, no sentido norte, caracterizada pela ascensão de uma anomalia de menor resistividade dentro de horizontes mais resistivos, sugere a ocorrência local de uma estrutura de falha, a qual estaria afetando todo o pacote estratigráfico. Esta observação é respaldada pela ocorrência de uma proeminente estruturação regional em todo o litoral leste do Rio Grande do Norte, principalmente nas direções SW-NE e SE-NW (Lucena, 2006; Nogueira et al., 2006). Somado a isso, nas proximidades do levantamento geoelétrico (cerca de 50 metros no sentido leste), particularmente, observa-se o afloramento do lençol freático (a denominação da localidade como Olho D'água provavelmente decorre dessa observação), além de uma escarpa com características de falha em um afloramento da Formação Barreiras.

Embora os dois arranjos de eletrodos utilizados na aquisição dos dados tenham apresentado resultados satisfatórios, inclusive com o Schlumberger apresentando mais proeminente as variações residuais de resistividades, pode-se afirmar que o resultado obtido com o arranjo Wenner mostrou-se mais consistente com o contexto hidroestratigráfico local. Esta observação foi corroborada pela ocorrência de um solo local aproximadamente homogêneo, além de considerar uma maior susceptibilidade do arranjo Wenner à diferença de potencial nos respectivos eletrodos (com espaçamentos uniformes), sobretudo quando se procurou evidenciar a estrutura de camadas plano-paralelas.

A vulnerabilidade local do Aqüífero Barreiras foi avaliada preliminarmente na área da localidade de Olho D’Água (ver figura 1), a partir dos dados geoelétricos ora reportados. Considerando valores representativos de resistividades da zona não saturada do Aqüífero Barreiras estabelecidas por Lucena (2005) e da profundidade do topo do lençol freático (obtida com o modelo de inversão da figura 3), pode-se verificar um índice de vulnerabilidade predominantemente alto, principalmente para uma litologia dessa zona não saturada constituída por areias eólicas, coberturas arenosas, solos indiferenciados e/ou sedimentos aluvionares. Vale ressaltar que esta análise representa 
uma avaliação de caráter local e preliminar. Uma cartografia de vulnerabilidade do Aqüífero Barreiras de todo o setor oriental da bacia do Rio Catu-RN deverá incluir adicionalmente outros imageamentos geoelétricos, interpretação de sondagens elétricas verticais e dados de perfis de poços tubulares da área, os quais enfatizarão a profundidade do topo do aqüífero e litologia da zona não saturada sobrejacente.

\section{Conclusões}

Tendo como base os resultados ora reportados, a seção obtida com a configuração de eletrodos Wenner evidenciou um imageamento 2D mais compatibilizado com as feições geológicas (estratigrafia local aproximadamente plano-paralela e a sugestão de uma estrutura de falha) e hidrogeológicas (contato entre as zonas saturada e não saturada e a respectiva profundidade do topo do aqüífero) locais, sobretudo quando tais informações destinaram-se a uma análise de vulnerabilidade do Aqüífero Barreiras. As resistividades deste aqüífero são iguais ou inferiores a 400 Ohm.metro, enquanto que a zona não saturada sobreposta apresenta valores iguais ou superiores a 1000 Ohm.metro. Este contato, bem caracterizado nas seções geoelétricas revela uma espessura não saturada bastante reduzida (inferior a 15 metros), fato este que se reflete em uma elevada vulnerabilidade do aqüífero na área, frente a uma eventual disposição de contaminantes na superfície do terreno. A análise da vulnerabilidade local do Aqüífero Barreiras, embora represente uma abordagem bastante preliminar, tendo em vista fundamentar-se em um único imageamento geoelétrico, já evidencia um índice elevado, conforme as classes de vulnerabilidade propostas na metodologia GOD, frente ao uso intensivo de fertilização química na cultura regional da cana-deaçúcar. Por fim, considerando a importância do referido aqüífero como fonte do abastecimento do litoral leste do Rio Grande do Norte, o incremento do conhecimento de suas características hidrogeofísicas representa um importante subsídio numa gestão ambientalmente sustentável desse manancial.

\section{Agradecimentos}

Os autores agradecem ao Conselho Nacional de Desenvolvimento Científico e Tecnológico-CNPq pelo financiamento da presente pesquisa.

\section{Referências}

ASTIER, J.L. 1975. Geofisica aplicada a la hidrogeologia. Ed. Paraninfo, Madrid. 344 p.

CUSTÓDIO, E.; LLAMAS, M.R. 1983. Hidrologia Subterránea. Ed. Omega, $2^{\mathrm{a}}$ ed, Barcelona. 2 v.

FEITOSA, F.A.C. E MANOEL FILHO. 1997. Hidrogeologia - conceitos e aplicações. CPRM/REFO, LABHID-UFPE, $2^{\underline{a}}$ ed. Fortaleza. 391 p.
FOSTER, S.S.D. 1987. Fundamental concept in aquifer vulnerability, pollution risk and protection strategy; Vulnerability of soil and groundwater to pollution. In: INTERNATIONAL CONFERENCE HELD IN THE NETHERLANDS. TNO/RIVM, Committee on Hydrological Research, Delft, Netherlands. Proceedings and infortation. Pg: 69-86.

FOSTER, S.S.D.; HIRATA, R.A. 1988. Groundwater pollution risk assessment: a methodology using available data. WHO-PAHO/CEPIS WHO-PAHO/CEPIS, Lima. 81p.

GEOTOMO SOFTWARE. 2010. Geoelectrical Imaging 2D \& 3D - RES2DINV, ver. 3.59 for Windows XP/Vista/7. Rapid 2D Resistivity \& IP inversion using the leastsquares method. Geotomo Software, Penang, Malaysia. $151 \mathrm{p}$.

IPT. 1982. Estudo hidrogeológico regional detalhado do Estado do Rio Grande do Norte. Instituto de Pesquisas Tecnológicas do Estado de São Paulo S/A. Natal. 389 p. Secretaria de Indústria e Comércio do Estado do Rio Grande do Norte. Relatório técnico IPT nº 15.795.

LUCENA, L.R.F.; OLIVEIRA, S.K.; MEDEIROS, W.E. 1999. Condicionamento estrutural sobre o Aqüífero Barreiras e Sistema Lacustre do Bonfim, Nísia FlorestaRN. In: INTERNATIONAL CONGRESS OF THE BRASILIAN GEOPHYSICAL SOCIETY, Rio de Janeiro(RJ), Brasil. Anais... 1 CD-Rom.

LUCENA, L.R.F. 2005. Implicação da compartimentação estrutural no Aqüífero Barreiras na área da bacia do Rio Pirangi-RN. Tese de Doutorado, Universidade Federal do Paraná-UFPR. Curitiba. 151 p.

LUCENA, L.R.F.; ROSA FILHO, E.F.; HINDI, E.C. 2006. O controle estrutural no Aqüífero Barreiras - área da bacia do Rio Pirangi-RN. Revista Águas Subterrâneas, 20: p. 83-98

NOGUEIRA, F.C.C.; BEZERRA, F.H.R.; CASTRO, D.L. 2006. Deformação rúptil em depósitos da Formação Barreiras na porção leste da Bacia Potiguar. Geologia USP Série Científica, v. 6, n² 2, p. 51-59.

ORELLANA, E. 1972. Prospecion geoeletrica en corriente continua. Ed. Paraninfo, Madrid. 523 p. 


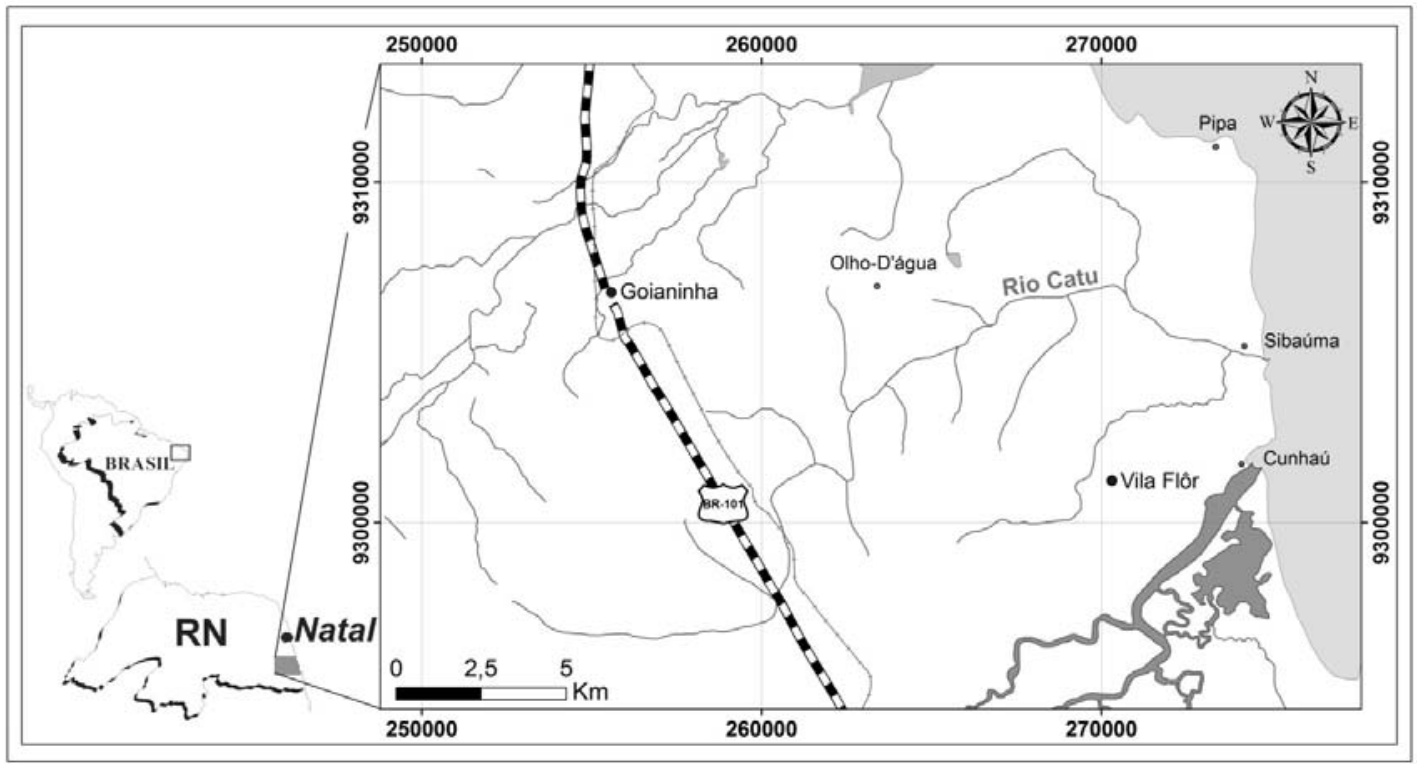

Figura 1 - Localização da área de estudo, setor oriental da bacia do Rio Catu-RN.

$1^{\text {a }}$ FASE: GRAU DE CONFINAMENTO DA ÁGUA SUBTERRÂNEA

\begin{tabular}{|c|c|c|c|c|c|}
\hline Ausência & $\begin{array}{l}\text { Confinado } \\
\text { artestiano }\end{array}$ & Confinado & Semiconfinado & $\begin{array}{l}\text { Năo confinado } \\
\text { (coberto) }\end{array}$ & Năo confinado \\
\hline ᄂ & & & & & \\
\hline
\end{tabular}

$2^{\text {a }}$ FASE: OCORRÊNCIA DE ESTRATOS DE COBERTURA

(características litológicas e grau de consolidação da zona não saturada)

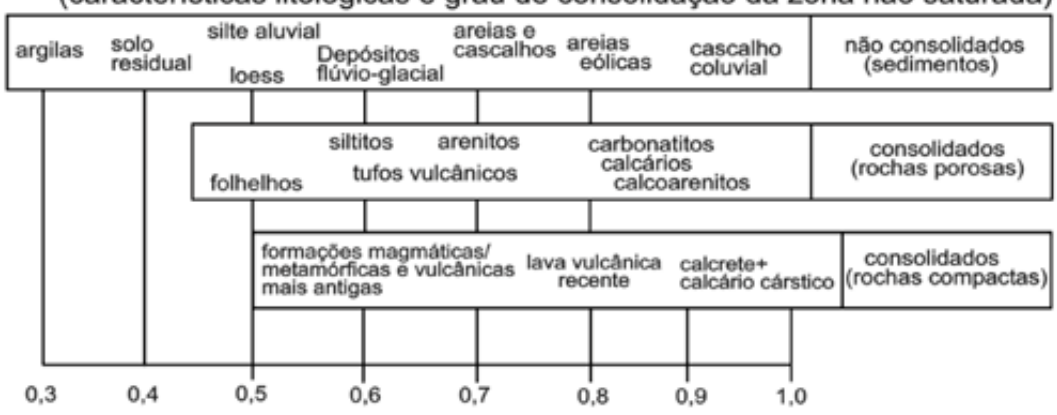

3ª FASE: DISTÂNCIA DA ÁGUA SUBTERRÂNEAẢ SUPERFICIE DO TERRENO

$$
\begin{array}{|c|c|c|c|}
\hline>50 \mathrm{~m} & 20-50 \mathrm{~m} & 5-20 \mathrm{~m} & <5 \mathrm{~m} \\
\hline 1 & 1 & 1 & 1,0 \\
0,4 & 0,6 & 0,8 & 1,0
\end{array}
$$

$4^{\mathrm{a}}$ FASE: ÍNDICE DE VULNERABILIDADE (produto das fases 1, 2 e 3 )

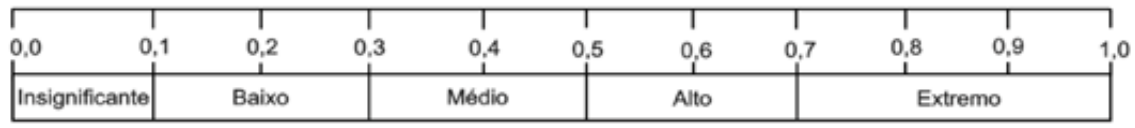

Figura 2 - Metodologia GOD para a determinação de vulnerabilidade de aqüíferos. 


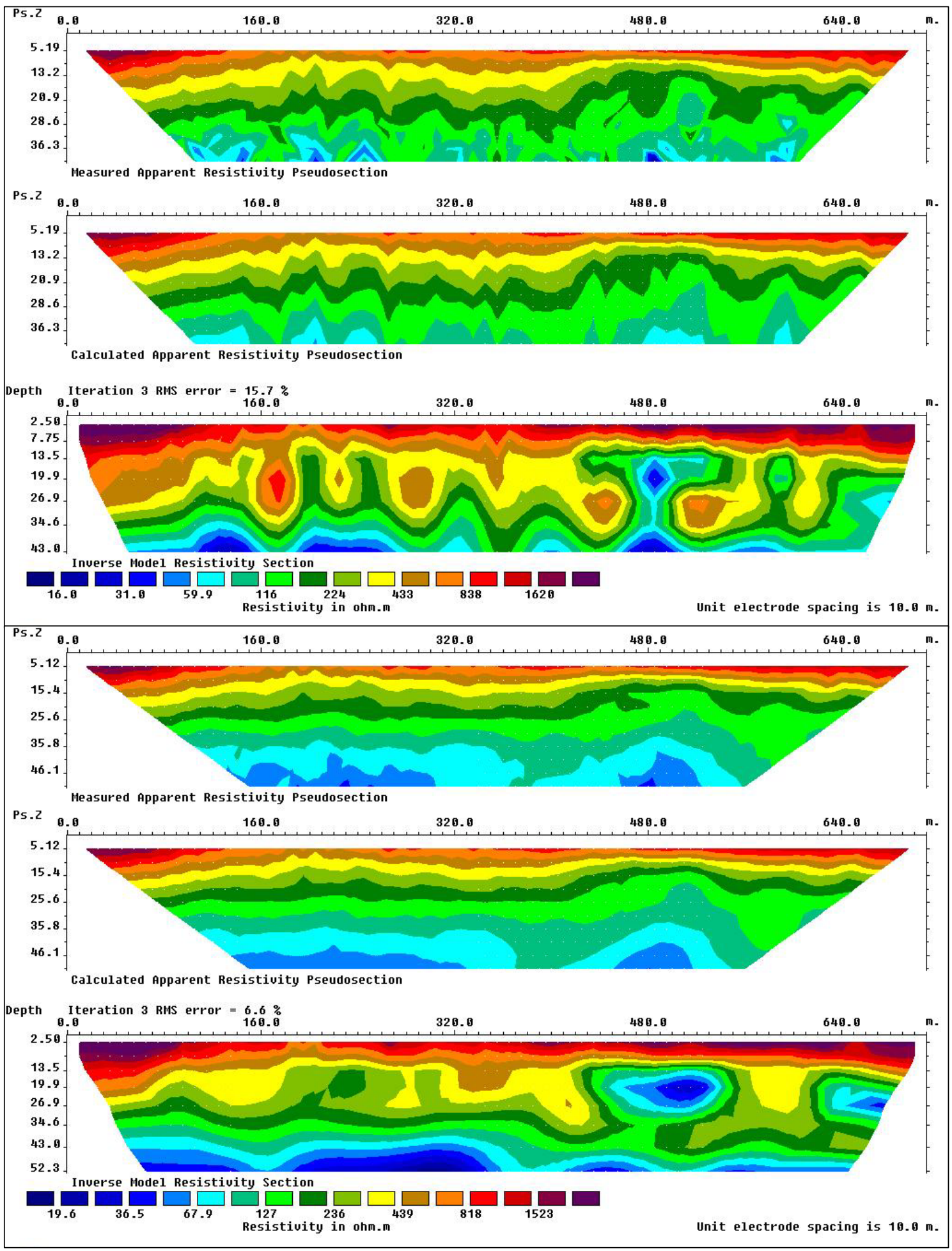

Figura 3 - Seções de resistividade obtidos a partir de modelos de inversão com as configurações de eletrodos Schlumberger (sequência superior) e Wenner (sequência inferior). 